\title{
Imaging for distant metastases in women with early-stage breast cancer: a population-based cohort study
}

\author{
Demetrios Simos MD, Christina Catley PhD, Carl van Walraven MD, Angel Arnaout MD, Christopher M. Booth MD, \\ Matthew McInnes MD, Dean Fergusson PhD, Susan Dent MD, Mark Clemons MD
}

CMAJ Podcasts: editor's summary at soundcloud.com/cmajpodcasts/150003-res

See also www.cmaj.ca/lookup/doi/10.1503/cmaj.150621

\section{- Abstract \\ Background: Practice guidelines recommend that imaging to detect metastatic disease not be performed in the majority of patients with early- stage breast cancer who are asymptomatic. We aimed to determine whether practice patterns in Ontario conform with these recommendations.}

Methods: We used provincial registry data to identify a population-based cohort of Ontario women in whom early-stage, operable breast cancer was diagnosed between 2007 and 2012. We then determined whether imaging of the skeleton, thorax, and abdomen or pelvis had been performed within 3 months of tissue diagnosis. We calculated rates of confirmatory imaging of the same body site.

Results: Of 26547 patients with early-stage disease, $22811(85.9 \%)$ had at least one imaging test, and a total of 83249 imaging tests were performed (mean of 3.7 imaging tests per patient imaged). Among patients with patho- logic stage I and II disease, imaging was performed in 79.6\% (10 921/13 724) and 92.7\% (11 882/12 823) of cases, respectively. Of all imaging tests, 19784 (23.8\%) were classified as confirmatory investigations. Imaging was more likely for patients who were younger, had greater comorbidity, had tumours of higher grade or stage or had undergone preoperative breast ultrasonography, mastectomy or surgery in the community setting.

Interpretation: Despite recommendations from multiple international guidelines, most Ontario women with early-stage breast cancer underwent imaging to detect distant metastases. Inappropriate imaging in asymptomatic patients with early-stage disease is costly and may lead to harm. The use of population datasets will allow investigators to evaluate whether or not strategies to implement practice guidelines lead to meaningful and sustained change in physician practice.
$\mathrm{M}$ ost women with newly diagnosed breast cancer present with earlystage, potentially curable disease. ${ }^{1}$ Among patients whose disease is restricted to the breast and axillary lymph nodes, without signs or symptoms of metastatic disease, the likelihood of having radiologically evident metastases in pathologic stage I and II disease is about $0.2 \%$ and $1.2 \%$, respectively. ${ }^{2}$ This low frequency has not changed significantly, even with the increasing use of magnetic resonance imaging (MRI) and positron emission tomography..$^{2,3}$ For this reason, most provincial, national and international guidelines do not recommend imaging for all patients with earlystage breast cancer who are asymptomatic. ${ }^{4-8}$

Despite these evidence-based guidelines, imaging for distant metastases in patients with a new diagnosis of breast cancer remains common. ${ }^{2,9-12}$ In response to the Choosing Wisely campaign of the American Board of Internal Medicine Foundation, ${ }^{13}$ the American Society of Clinical Oncology (ASCO) published its inaugural "top 5" list for choosing wisely in oncology. ${ }^{14}$ It recommended against routine imaging for staging purposes in women with early breast cancer, because "such imaging adds little benefit to patient care and has the potential to cause harm." 14 In 2014, Choosing Wisely Canada was launched in an effort to encourage physicians and patients to engage in conversations about unnecessary tests, treatments and procedures, to help ensure that patients receive the highest-quality care. ${ }^{15}$

The ASCO Choosing Wisely recommenda$\operatorname{tion}^{14}$ is similar to the Cancer Care Ontario guideline,${ }^{4}$ which has been in existence for over a decade. Whereas ASCO in its Choosing Wisely campaign recommends no imaging for patients with stage I or II disease, the Cancer Care Ontario guideline recommends no imaging for
Competing interests:

None declared.

This article has been peer reviewed.

Accepted: May 7, 2015

Online: June 22, 2015

Correspondence to: Mark Clemons, mclemons@toh.on.ca

CMAJ 2015. DOI:10.1503/ cmaj.150003 
patients with stage I disease and a bone scan for those with stage II disease. A recent study at a large Canadian academic cancer centre showed that, despite publication of both a provincial guideline and the ASCO recommendations, most patients with primary operable (early-stage) breast cancer undergo imaging for distant metastases. ${ }^{10}$ We hypothesized that despite the provincial guideline, this practice may be more widespread. We undertook this population-based study to determine whether physician practice patterns in Ontario regarding imaging of patients with early-stage breast cancer are in keeping with the published Cancer Care Ontario guideline.

\section{Methods}

We aimed to determine the extent and type of radiologic imaging that is being performed for assessment of distant metastases in patients with asymptomatic stage I or II breast cancer and to identify regional differences and factors that may be associated with a higher likelihood of imaging.

\section{Study population}

This retrospective, population-based cohort study was approved by the Sunnybrook Health Sciences
Centre Research Ethics Board. We linked data from population-based datasets available through the Institute for Clinical Evaluative Sciences to capture perioperative (i.e., before and after definitive breast cancer surgery) imaging studies for patients with primary operable (early-stage) breast cancer in Ontario. Complete study methods are provided in Appendix 1 (available at www.cmaj. ca/lookup/suppl/doi:10.1503/cmaj.150003/-/DC1), and health codes are available in Appendix 2 (available at www.cmaj.ca/lookup/suppl/doi: 10.1503/cmaj.150003/-/DC1).

We used the Ontario Cancer Registry to identify all women with a diagnosis of stage I (I, IA and IB) or stage II (II, IIA and IIB) breast cancer (Table 1) ${ }^{16}$ between 2007 and 2012, with 2012 being the last year that data from the Ontario Cancer Registry were available at the Institute for Clinical Evaluative Sciences. The cancer stage recorded in the registry is determined from electronic medical records after all of the patient's results have been received; as such, staging as recorded in the registry is considered the "best available" stage.

We excluded patients who had a prior breast cancer diagnosis and those who had stage 0, III or IV disease, or null or unknown stage disease.

Table 1: Description of breast cancer staging ${ }^{16}$

\begin{tabular}{|c|c|}
\hline Stage & Description \\
\hline \multicolumn{2}{|c|}{ Noninvasive } \\
\hline 0 & $\begin{array}{l}\text { No evidence of cancer cells or invasion of the basement membrane of the duct or } \\
\text { neighbouring normal tissue; includes ductal carcinoma in situ }\end{array}$ \\
\hline \multicolumn{2}{|c|}{ Invasive } \\
\hline IA & $\begin{array}{l}\text { - Tumour } \leq 2 \mathrm{~cm} \text { AND } \\
\text { - No spread outside the breast; no lymph nodes involved }\end{array}$ \\
\hline IB & $\begin{array}{l}\text { - No tumour in the breast, but microscopic metastases }(>0.2 \mathrm{~mm} \text { but } \leq 2 \mathrm{~mm} \text { ) present } \\
\text { in axillary lymph nodes OR } \\
\text { - Tumour present in the breast, } \leq 2 \mathrm{~cm} \text {, with involvement of lymph nodes }\end{array}$ \\
\hline IIA & $\begin{array}{l}\text { - No tumour in the breast, but macroscopic cancer ( }>2 \mathrm{~mm} \text { ) in 1-3 axillary lymph } \\
\text { nodes OR } \\
\text { - Tumour } \leq 2 \mathrm{~cm} \text {, with spread to axillary lymph nodes OR } \\
\text { - Tumour }>2 \mathrm{~cm} \text { but } \leq 5 \mathrm{~cm} \text {, with no spread to axillary lymph nodes }\end{array}$ \\
\hline IIB & $\begin{array}{l}\text { - Tumour }>2 \mathrm{~cm} \text { but } \leq 5 \mathrm{~cm} \text {, with spread to } 1-3 \text { axillary lymph nodes OR } \\
\text { - Tumour }>5 \mathrm{~cm} \text {, with no spread to axillary lymph nodes }\end{array}$ \\
\hline IIIA & $\begin{array}{l}\text { - No tumour in the breast or presence of a breast tumour of any size associated with } \\
\text { metastases in 4-9 axillary lymph nodes or in internal mammary nodes OR } \\
\text { - Tumour }>5 \mathrm{~cm} \text {, with spread to axillary and/or internal mammary nodes }\end{array}$ \\
\hline IIIB & $\begin{array}{l}\text { - Tumour of any size, with spread to chest wall and/or skin of the breast; may also } \\
\text { have spread to axillary or internal mammary nodes }\end{array}$ \\
\hline IIIC & $\begin{array}{l}\text { - Tumour of any size, with spread to } \geq 10 \text { axillary lymph nodes OR } \\
\text { - Spread to lymph nodes above or below the collarbone (supraclavicular nodes) OR } \\
\text { - Spread to both axillary lymph nodes and internal mammary nodes }\end{array}$ \\
\hline \multicolumn{2}{|c|}{ Metastatic } \\
\hline IV & Spread of cancer to other parts of the body such as liver, lung or bone \\
\hline
\end{tabular}


We also excluded cases of ductal carcinoma in situ because the Institute for Clinical Evaluative Sciences does not receive information about such cases from the Ontario Cancer Registry.

The registry cohort was linked with the Discharge Abstract Database of the Canadian Institute for Health Information to identify patients who underwent breast-related surgery. To identify patients with primary operable disease, we restricted the study population to patients with a first diagnosis of breast cancer who underwent definitive surgery within 3 months of the tissue diagnosis date. This window was selected to exclude patients who might have received preoperative systemic therapy for initially inoperable, locally advanced disease, since contemporary preoperative chemotherapy regimens are a minimum of 4-5 months in duration. ${ }^{17}$ The plan for creating the cohort dataset is shown in Figure 1.

\section{Factors associated with imaging}

To identify factors associated with utilization of imaging, patient-level data were collected for age at diagnosis, disease stage, histologic findings (characterized as ductal, lobular or other), comorbidity (calculated using the Deyo modification of the Charlson comorbidity index ${ }^{18}$ and characterized as $0,1-2$ or $\geq 3$ ), surgery type, whether additional preoperative locoregional imaging beyond mammography was performed (either breast ultrasonography or breast MRI), and neighbourhood income quintile based on Postal Code Conversion File Plus. ${ }^{19}$ Information about institution type, rurality of the patient's residence (based on the Rurality Index for Ontario 2008 ${ }^{20}$ and the Local Health Integration Network (LHIN) of the hospital performing the surgery was also collected. Ontario is divided geographically into 14 LHINs, which administer and coordinate local health systems. ${ }^{21}$ For additional disease characteristics not available in the Ontario Cancer Registry (i.e., tumour grade [1,2 or 3], human epidermal receptor-2 [HER2] status [positive or negative], presence of triple-negative disease [i.e., negative for estrogen receptors, progesterone receptors and HER2 status; yes or no], involvement of axillary lymph nodes [yes or no] and presence of lymphovascular invasion [yes or no]), we linked to the Ontario Cancer Registry's Collaborative Staging dataset.

\section{Imaging quantification and classification}

To quantify all perioperative imaging performed for the purpose of staging, we linked the cohort of patients with primary operable breast cancer with the Ontario Health Insurance Plan (OHIP) database to obtain all imaging fee codes (see Appendix 2, Part 2) associated with these patients. Imaging was considered preoperative if it occurred between the tissue diagnosis date and the day of surgery; imaging was considered postoperative if it occurred within the 3-month window after the definitive breast surgical procedure. All imaging tests were classified by site (skeleton, thorax, abdomen and/or pelvis, other) and modality.

We further classified imaging tests as initial imaging or confirmatory imaging. Initial imaging was defined as the first imaging test performed on a body site (i.e., skeleton, thorax, abdomen and/or pelvis, other) in the prespecified time period. Confirmatory imaging was defined as any additional imaging test performed on a body site that had already been imaged. We did not count any imaging of the same anatomic body area beyond the first confirmatory scan in the total imaging counts. We adopted this conservative approach in an effort to reduce the chance of including further imaging unrelated to breast cancer staging. To determine who ordered the imaging test, we extracted the referring physician's self-reported main specialty associated with the OHIP imaging fee code.

\section{Statistical analysis}

We calculated the total numbers of initial and confirmatory imaging tests for patients with stage I or II breast cancer, considering both the number of patients imaged and the number of imaging

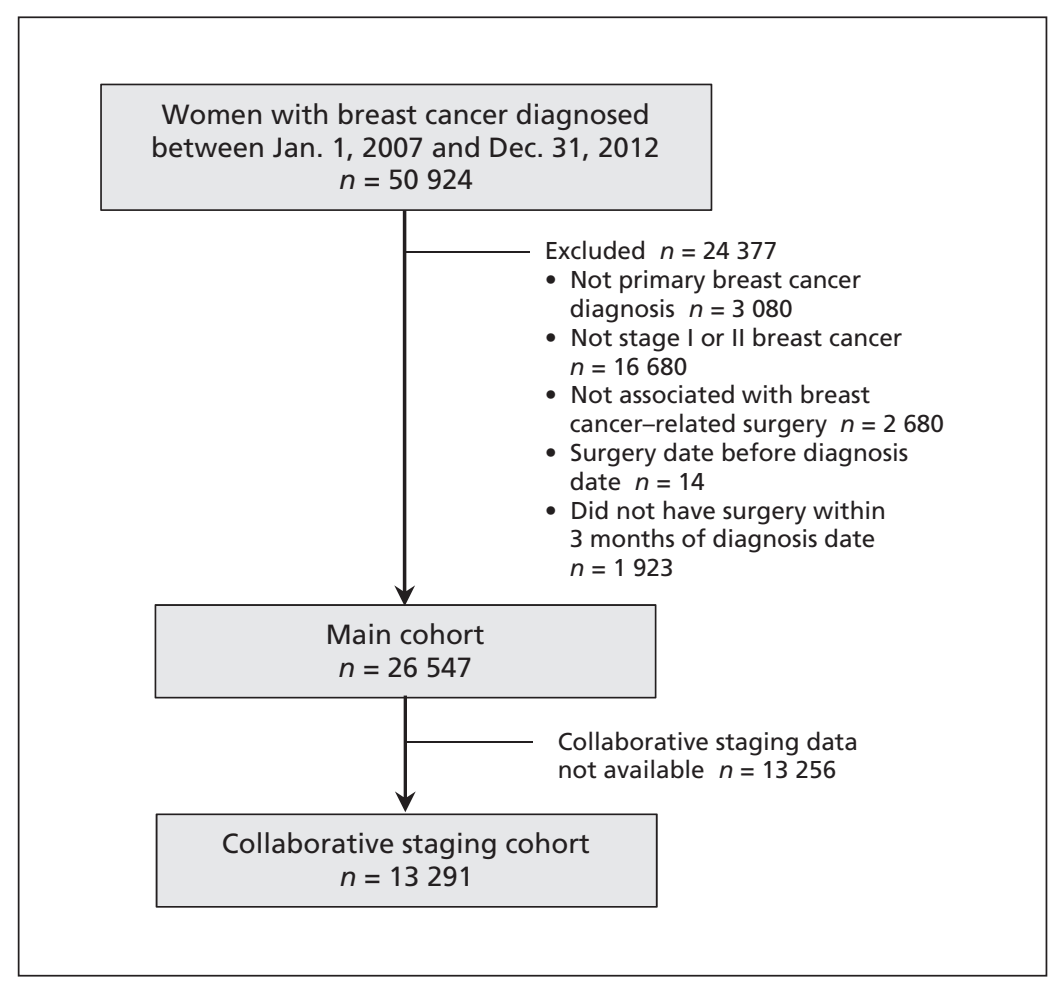

Figure 1: Creation of a population-based cohort to investigate the frequency of imaging for distant metastases among women with early-stage breast cancer. 
Table 2: Characteristics of women with early-stage breast cancer treated with surgery in Ontario, 2007 to 2012

\section{Cohort; no. (\%) of patients*}

\begin{tabular}{|c|c|c|}
\hline Characteristic & $\begin{array}{l}\text { Full cohort } \\
(n=26547)\end{array}$ & $\begin{array}{l}\text { Collaborative staging cohort } \\
\qquad(n=13291)\end{array}$ \\
\hline \multicolumn{3}{|l|}{ Patient-related factors } \\
\hline \multicolumn{3}{|l|}{ Age at diagnosis, yr } \\
\hline$<40$ & $1036 \quad(3.9)$ & $499 \quad(3.8)$ \\
\hline $40-49$ & $4292(16.2)$ & $2090(15.7)$ \\
\hline $50-59$ & $6818(25.7)$ & 3359 (25.3) \\
\hline $60-69$ & $7180(27.0)$ & $3548(26.7)$ \\
\hline 70-79 & $4717(17.8)$ & $2420(18.2)$ \\
\hline$\geq 80$ & $2504 \quad(9.4)$ & $1375(10.3)$ \\
\hline \multicolumn{3}{|c|}{ Socioeconomic status, by income quintile +} \\
\hline 1 (lowest) & $4506(17.0)$ & $2291(17.3)$ \\
\hline 2 & $5158(19.5)$ & $2537(19.1)$ \\
\hline 3 & $5073(19.2)$ & $2546(19.2)$ \\
\hline 4 & $5706(21.6)$ & $2858(21.6)$ \\
\hline 5 (highest) & $6012(22.7)$ & $3019(22.8)$ \\
\hline \multicolumn{3}{|l|}{ Charlson comorbidity score } \\
\hline 0 & $19054(71.8)$ & $9614(72.3)$ \\
\hline $1-2$ & $2106(7.9)$ & $1046 \quad(7.9)$ \\
\hline$\geq 3$ & $5387(20.3)$ & $2631(19.8)$ \\
\hline \multicolumn{3}{|c|}{ Rurality of residence at diagnosis } \\
\hline Urban & $24299(91.5)$ & $12110(91.1)$ \\
\hline Rural & $2248 \quad(8.5)$ & $1181 \quad(8.9)$ \\
\hline \multicolumn{3}{|l|}{ Disease-related factors } \\
\hline \multicolumn{3}{|l|}{ Stage } \\
\hline I & $13724(51.7)$ & $6836(51.4)$ \\
\hline II & $12823(48.3)$ & $6455(48.6)$ \\
\hline \multicolumn{3}{|l|}{ Histology } \\
\hline Ductal & $18897(71.2)$ & $9375(70.5)$ \\
\hline Lobular & $1638(6.2)$ & $866 \quad(6.5)$ \\
\hline Mixed or other & $6012(22.6)$ & $3050(22.9)$ \\
\hline \multicolumn{3}{|l|}{ Tumour grade§ } \\
\hline 1 & - & $3095(23.3)$ \\
\hline 2 & - & $5751(43.3)$ \\
\hline 3 & - & $3591(27.0)$ \\
\hline Missing & - & $854 \quad(6.4)$ \\
\hline \multicolumn{3}{|l|}{ HER2 status§ } \\
\hline Positive & - & 1126 \\
\hline Negative & - & 12165 (91.5) \\
\hline \multicolumn{3}{|c|}{ Axillary lymph node involvement§ } \\
\hline No & - & $10119(76.1)$ \\
\hline Yes & - & $3172(23.9)$ \\
\hline \multicolumn{3}{|l|}{ Lymph or vascular invasion§ } \\
\hline Absent & - & $11137(83.8)$ \\
\hline Present & - & $2154(16.2)$ \\
\hline \multicolumn{3}{|l|}{ Triple-negative disease§ } \\
\hline Absent & - & $11837(89.1)$ \\
\hline Present & - & $1454(10.9)$ \\
\hline \multicolumn{3}{|c|}{ Preoperative breast ultrasonography } \\
\hline No & $1474 \quad(5.6)$ & $638(4.8)$ \\
\hline Yes & $25073(94.4)$ & $12653(95.2)$ \\
\hline \multicolumn{3}{|l|}{ Preoperative breast MRI } \\
\hline No & $20431(77.0)$ & $9972(75.0)$ \\
\hline Yes & $6116(23.0)$ & $3319(25.0)$ \\
\hline \multicolumn{3}{|l|}{ Surgery type } \\
\hline Breast-conserving & $19794(74.6)$ & $9828(73.9)$ \\
\hline Non-breast-conserving & $6753(25.4)$ & $3463(26.1)$ \\
\hline \multicolumn{3}{|c|}{ System-related factors } \\
\hline Hospital type where surg & & \\
\hline Academic & $8400(31.6)$ & $3919(29.5)$ \\
\hline Community & $18147(68.4)$ & $9372(70.5)$ \\
\hline $\begin{array}{l}\text { Note: HER2 = human epide } \\
\text { *Percentages may not sum } \\
\text { tQuintile } 1 \text { included patien } \\
\text { were missing for } 92 \text { patien } \\
\text { ‡Based on Rurality Index fo } \\
\text { §Covariables that were ava }\end{array}$ & $\begin{array}{l}\text { nance imaging. } \\
\text { le lowest socioecc } \\
\text { s in the "collabor } \\
\text { only. }\end{array}$ & $\begin{array}{l}\text { Data for socioeconomic status } \\
\text { cohort. }\end{array}$ \\
\hline
\end{tabular}


tests performed. Initial and confirmatory imaging was further classified into pre- and postoperative imaging. All initial and confirmatory imaging tests were quantified by body site and imaging modality. To assess whether the use of imaging modalities changed over time, the proportion of patients imaged each year was calculated by body site and across all body sites, considering initial and confirmatory imaging separately. Trends were evaluated using the Cochran-Armitage test.

To identify characteristics potentially associated with imaging for metastatic disease, we used multivariable logistic regression to examine the association between the covariables and imaging at any site (skeleton, thorax, abdomen and/or pelvis, other) and at each site individually For the purpose of this analysis, imaging for metastases did not include any imaging performed on the breast, such as ultrasonography, MRI or mammography. All statistical analyses were performed using SAS software, version 9.3 (SAS Institute).

\section{Results}

\section{Patient characteristics}

Between 2007 and 2012, a total of 26547 women in Ontario were identified with stage I $(51.7 \%)$ or stage II $(48.3 \%)$ breast cancer (Table 2). Eighty percent of the patients were at least 50 years old. Locoregional staging with breast MRI was performed in $23.0 \%$ of the patients, and $74.6 \%$ underwent breast-conserving surgery.

\section{Imaging performed}

Of the 26547 patients, 22811 (85.9\%) had at least one imaging test for distant metastatic disease (Table 3 and Appendix 3, available at www. cmaj.ca/lookup/suppl/doi:10.1503/cmaj.150003/-/ DC1). Imaging was performed in 10921 (79.6\%) and $11882(92.7 \%)$ of women with stage I and II disease, respectively. The total number of imaging tests was 83249 . Overall, $76.2 \%$ of these ( $n=$ $63465)$ were classified as initial imaging, and $23.8 \%$ ( $n=19784$ ) were classified as confirmatory imaging. On average, 3.6 (standard deviation 1.9) imaging tests were performed per patient who underwent imaging. Nearly half of the initial imaging was performed in the preoperative period (48.7\%, 30 907/63 465), whereas most of the confirmatory imaging was performed postoperatively (79.1\%, 15 647/19 784).

\section{Provider characteristics}

In the preoperative setting, initial imaging was ordered mainly by the surgeon $(73.9 \%$ of imaging tests), the primary care physician (19.9\%), the medical oncologist $(1.1 \%)$ or the radiation

Table 3: Initial and confirmatory imaging for women with early-stage breast cancer treated with surgery in Ontario, 2007 to 2012

\begin{tabular}{|c|c|c|c|c|c|}
\hline \multirow[b]{2}{*}{ Stage of disease } & \multicolumn{2}{|c|}{ Initial imaging } & \multicolumn{2}{|c|}{ Confirmatory imaging } & \multirow[b]{2}{*}{ Overall } \\
\hline & Preoperative & Postoperative & Preoperative & Postoperative & \\
\hline \multicolumn{6}{|l|}{ Stage I ( $n$ = 13724 patients) } \\
\hline $\begin{array}{l}\text { No. of tests/patient imaged, }{ }^{*} \\
\text { mean } \pm \text { SD }\end{array}$ & & & & & $3.2 \pm 1.8$ \\
\hline $\begin{array}{l}\text { No. }(\%) \text { of patients with } \\
\text { stage I disease imaged }\end{array}$ & $7768(56.6)$ & $6197(45.2)$ & $1461(10.6)$ & $3918(28.5)$ & $10921 \quad(79.6)$ \\
\hline No. $(\%)$ of stage I tests & $14510(41.1)$ & $12911(36.6)$ & 1885 & 5967 (16.9) & $35273(100.0)$ \\
\hline \multicolumn{6}{|l|}{ Stage II ( $n=12823$ patients) } \\
\hline $\begin{array}{l}\text { No. of tests/patient imaged, * } \\
\text { mean } \pm S D\end{array}$ & & & & & $4.0 \pm 1.9$ \\
\hline $\begin{array}{l}\text { No. (\%) of patients with } \\
\text { stage II disease imaged }\end{array}$ & $7951(62.0)$ & $8196(63.9)$ & $1632(12.7)$ & $5831(45.5)$ & $11882 \quad(92.7)$ \\
\hline No. $(\%)$ of stage II tests & $16397(34.2)$ & $19647(41.0)$ & 2252 & $9680(20.2)$ & $47976(100.0)$ \\
\hline \multicolumn{6}{|c|}{ All stages ( $n=26547$ patients) } \\
\hline $\begin{array}{l}\text { No. of tests/patient imaged, }{ }^{*} \\
\text { mean } \pm \text { SD }\end{array}$ & & & & & $3.6 \pm 1.9$ \\
\hline $\begin{array}{l}\text { No. (\%) of all patients } \\
\text { imaged }\end{array}$ & $15719(59.2)$ & $14393(54.2)$ & $3093(11.7)$ & $9749(36.7)$ & $22811 \quad(85.9)$ \\
\hline No. (\%) of all tests & 30907 (37.1) & $32558(39.1)$ & $4137 \quad(5.0)$ & $15647(18.8)$ & $83249(100.0)$ \\
\hline
\end{tabular}


oncologist (0.3\%) (Table 4). Postoperatively, the relative proportions of initial imaging ordered by surgeons $(42.6 \%)$ and primary care physicians $(11.4 \%)$ declined, and the proportions ordered by medical oncologists $(35.0 \%)$ and radiation oncologists $(6.2 \%)$ increased.

\section{Imaging trends over time}

The overall total proportion of patients with breast cancer who underwent conventional and advanced imaging remained relatively stable over the study period; however, there was a trend toward the use of more advanced imaging (i.e., computed tomography $[\mathrm{CT}]$ and MRI) and a decline in the use of conventional imaging over time. Figure 2 contrasts conventional and advanced imaging modalities for each body site. For example, the use of thoracic radiography for initial imaging of patients with stage II cancer (Figure 2B) declined from 80\% in 2007 to 63\% in 2012, whereas the use of thoracic CT increased steadily, from $3 \%$ to $19 \%$ over the same period (trend for all stages, $p<0.001$ ). A similar pattern was observed for abdominal and pelvic imaging (Figure 2C), where the use of ultrasonography for initial imaging declined, while use of CT increased (trend for all stages, $p<0.001$ ) (see Appendix 4, available at www.cmaj.ca/lookup/ suppl/doi:10.1503/cmaj.150003/-/DC1). Overall, use of advanced imaging (i.e., isotope bone scans, CT, MRI, positron emission tomography) to look at potential sites of metastasis represented $40.6 \%$ (25 776) of initial imaging tests; see Appendix 3 for details.

\section{Factors associated with imaging}

Multivariable analysis was performed on the subset of 13291 patients for whom collaborative staging data were available (50.1\% of full study cohort). Associated odds ratios (OR) and 95\% confidence intervals are presented in Table 5. A number of patient-related (younger age, greater comorbidities), disease-related (higher-stage tumour, negative HER2 status, involvement of axillary lymph nodes, lymph or vascular invasion, locoregional breast staging, imaging beyond mammography [i.e., ultrasonography], non-breast-conserving surgery) and systemrelated (surgery performed in the community) factors were associated with greater use of imaging. We also found significant associations between geographic status (by LHIN) and use of imaging, both overall and by body site.

To verify that there were no significant differences between cohorts, we performed multivariable analysis for both cohorts, using only those variables available for the full cohort. The results were not significantly different (data not shown).

\section{Interpretation}

Despite guidelines against imaging to detect radiologically evident distant metastases, our results show that this practice is very common among patients with early-stage breast cancer in Ontario. ${ }^{4-6,8}$ The reasons for this disconnect between evidence and practice are likely attributable to a combination of patient-related ${ }^{11}$ and physician-related ${ }^{22}$ factors. It is not surprising, given the low pretest probability of detecting disease, that ASCO highlighted this practice disparity in its inaugural "top 5" list for choosing wisely in oncology. ${ }^{14}$ The ASCO document stresses that the routine use of imaging for staging in asymptomatic patients with early-stage disease does not extend survival, is costly and may lead to harm (since false-positive results may lead to invasive procedures and overtreatment), all of which can impair quality of life.

A recent single-centre study showed that the ASCO publication had no impact on the overuse of imaging for staging purposes. ${ }^{10}$ Our current study confirms that nonadherence with evidencebased guidelines is common across Ontario. According to guidelines, asymptomatic patients

Table 4: Main specialty of referring physician

\begin{tabular}{|c|c|c|c|c|}
\hline \multirow[b]{2}{*}{ Specialty } & \multicolumn{2}{|c|}{ No. (\%) of initial imaging tests* } & \multicolumn{2}{|c|}{ No. $(\%)$ of confirmatory imaging tests* } \\
\hline & Preoperative & Postoperative & Preoperative & Postoperative \\
\hline Surgery & 22588 (73.9) & 13596 (42.6) & $2478 \quad(60.7)$ & 3743 (24.4) \\
\hline Medical oncology & $336 \quad(1.1)$ & 11203 (35.1) & $(1.5)$ & 5968 (38.9) \\
\hline Radiation oncology & $(0.3)$ & $1979 \quad(6.2)$ & $(0.3)$ & $890 \quad(5.8)$ \\
\hline Primary care & 6082 (19.9) & 3638 (11.4) & $1172(28.7)$ & 3743 (24.4) \\
\hline Diagnostic imaging & $(2.0)$ & $(1.0)$ & $(4.3)$ & $(2.0)$ \\
\hline Other & $856 \quad(2.8)$ & 1181 & $(4.5)$ & $(4.5)$ \\
\hline Total & $30565(100.0)$ & $31916(100.0)$ & $4083(100.0)$ & $15341(100.0)$ \\
\hline
\end{tabular}




\section{A: Skeleton}

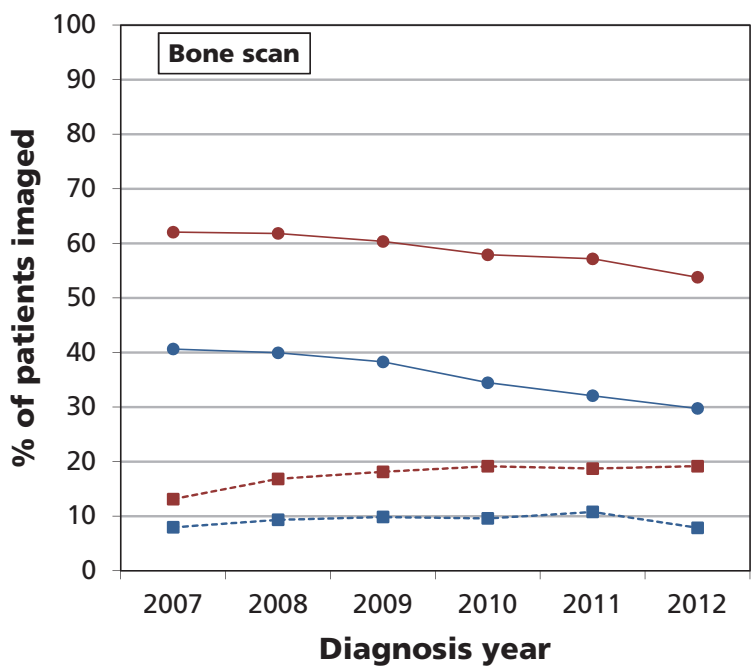

\section{B: Thorax}

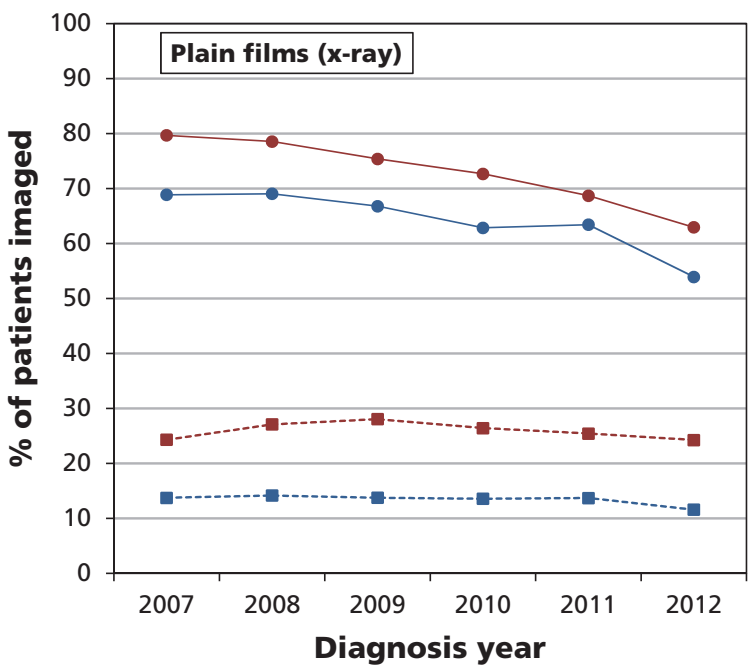

\section{C: Abdomen and/or pelvis}

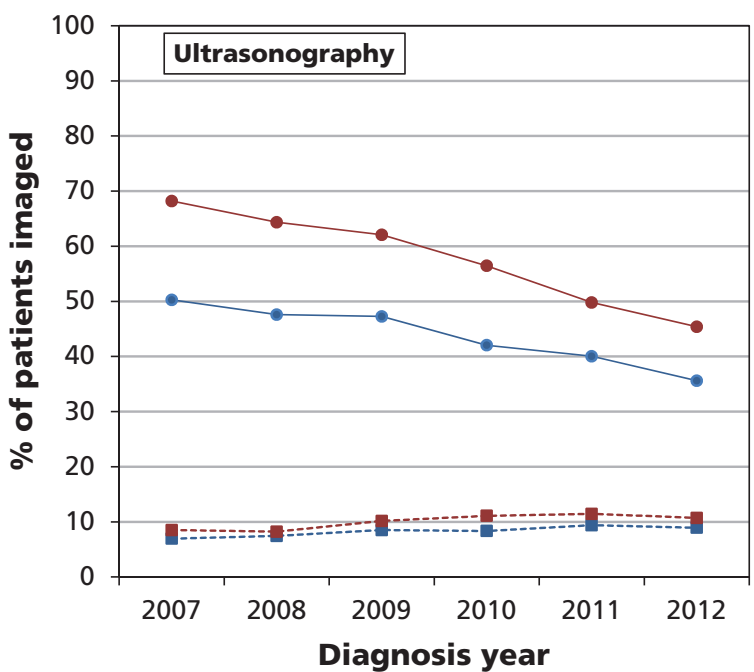

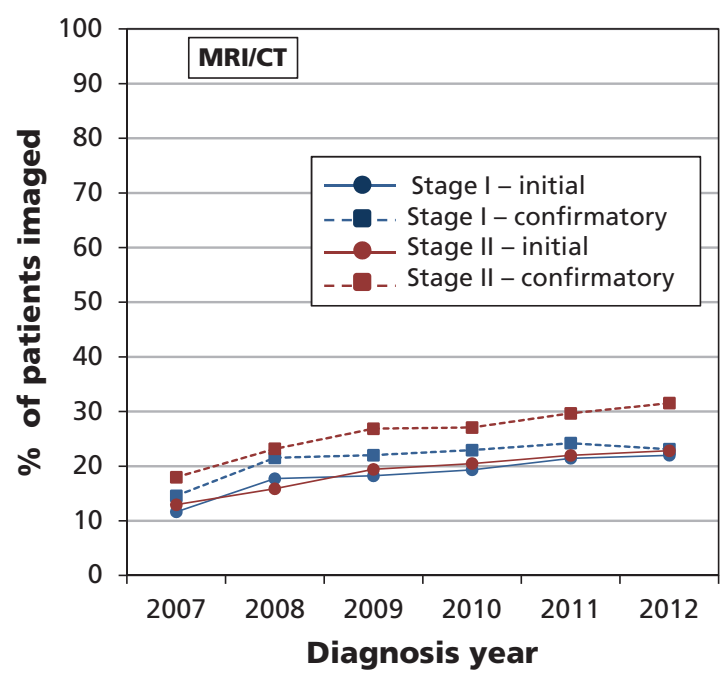
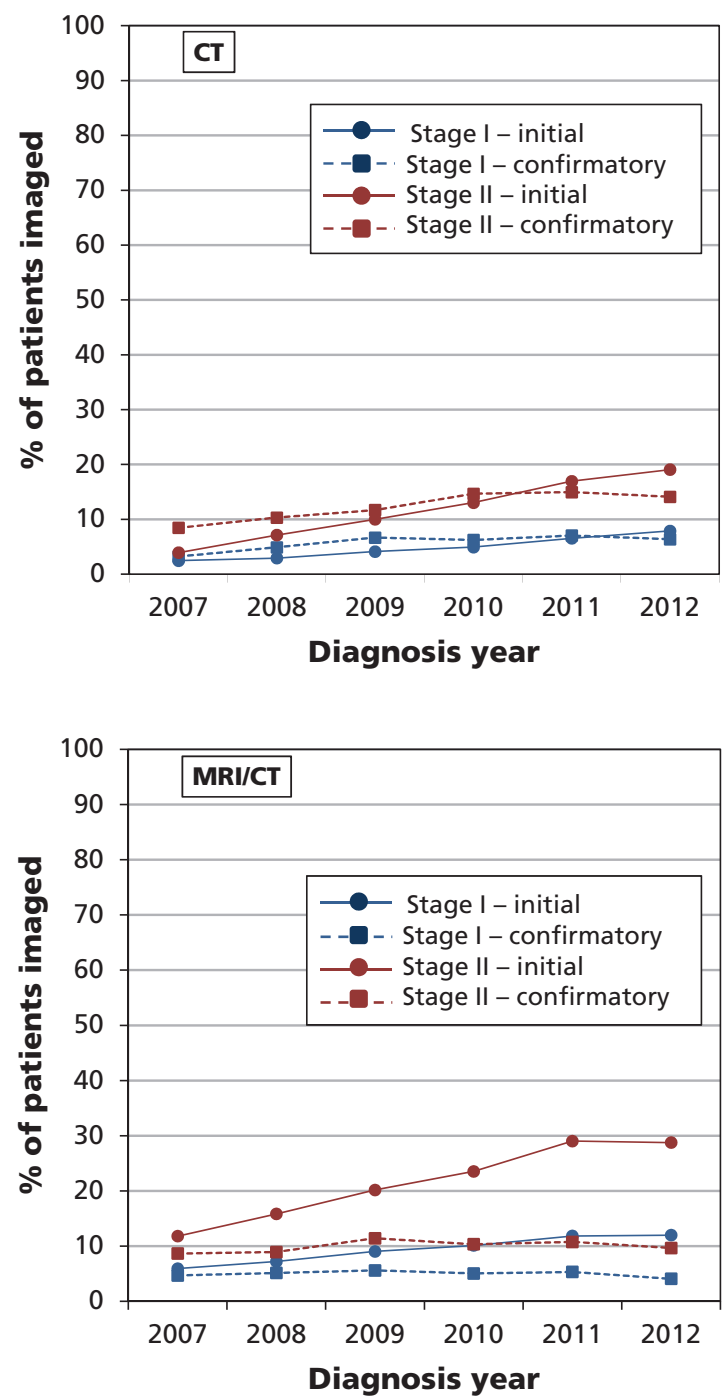

Figure 2: Yearly imaging trends for skeleton (A), thorax (B) and abdomen and/or pelvis (C) by conventional imaging (at left) and more advanced imaging (at right). CT = computed tomography, MRI = magnetic resonance imaging. 
Table 5: Estimated odds of imaging at specific body sites or all sites, for women with collaborative staging data (part 1 of 2)

\begin{tabular}{|c|c|c|c|c|c|}
\hline Variable & \multicolumn{5}{|c|}{ Body site; OR $(95 \% \mathrm{Cl})$} \\
\hline \multicolumn{6}{|c|}{ Age at diagnosis, yr } \\
\hline$<40$ & Reference & Reference & Reference & Reference & Reference \\
\hline $50-59$ & $0.77(0.53-1.12)$ & $0.69(0.53-0.89)$ & $0.84(0.64-1.11)$ & $0.62(0.48-0.81)$ & $0.92(0.61-1.39)$ \\
\hline $60-69$ & $0.68(0.47-0.98)$ & $0.60(0.46-0.79)$ & $0.83(0.63-1.10)$ & $0.49(0.38-0.64)$ & $0.76(0.50-1.16)$ \\
\hline $70-79$ & $0.59(0.40-0.86)$ & $0.46(0.35-0.60)$ & $0.70(0.52-0.93)$ & $0.40(0.31-0.53)$ & $0.69(0.44-1.08)$ \\
\hline$>80$ & $0.33(0.22-0.48)$ & $0.24(0.18-0.32)$ & $0.45(0.34-0.61)$ & $0.21(0.16-0.27)$ & $0.39(0.23-0.68)$ \\
\hline \multicolumn{6}{|c|}{ Socioeconomic status, by income quintile } \\
\hline 4 & $0.86(0.72-1.02)$ & $0.94(0.83-1.07)$ & $0.95(0.82-1.09)$ & $0.91(0.80-1.04)$ & $0.96(0.73-1.26)$ \\
\hline 5 (highest) & $0.79(0.67-0.93)$ & $0.96(0.85-1.10)$ & $0.83(0.73-0.96)$ & $0.97(0.85-1.10)$ & $0.86(0.65-1.13)$ \\
\hline \multicolumn{6}{|c|}{ Charlson comorbidity score } \\
\hline 0 & Reference & Reference & Reference & Reference & Reference \\
\hline $1-2$ & $1.11(0.92-1.33)$ & $0.98(0.84-1.13)$ & $1.12(0.96-1.32)$ & $0.95(0.83-1.10)$ & $1.55(1.12-2.14)$ \\
\hline$\geq 3$ & $1.74(1.34-2.25)$ & $1.64(1.39-1.94)$ & $1.55(1.28-1.88)$ & $1.59(1.36-1.87)$ & $1.65(1.23-2.23)$ \\
\hline \multicolumn{6}{|c|}{ Rurality of residence at diagnosis } \\
\hline Urban & Reference & Reference & Reference & Reference & Reference \\
\hline \multicolumn{6}{|l|}{ Histology } \\
\hline Ductal & Reference & Reference & Reference & Reference & Reference \\
\hline Lobular & $1.19(0.96-1.48)$ & $1.25(1.06-1.47)$ & $1.03(0.86-1.23)$ & $0.95(0.81-1.11)$ & $0.87(0.57-1.32)$ \\
\hline Mixed/other & $0.96(0.85-1.08)$ & $1.09(0.99-1.20)$ & $0.91(0.82-1.00)$ & $0.96(0.88-1.06)$ & $0.84(0.67-1.07)$ \\
\hline \multicolumn{6}{|l|}{ Tumour grade } \\
\hline 1 & Reference & Reference & Reference & Reference & Reference \\
\hline 2 & $1.21(1.07-1.37)$ & $1.29(1.17-1.42)$ & $1.19(1.07-1.33)$ & $1.30(1.18-1.43)$ & $0.99(0.76-1.28)$ \\
\hline 3 & $1.67(1.41-1.98)$ & $1.63(1.44-1.86)$ & $1.60(1.38-1.84)$ & $1.53(1.34-1.74)$ & $1.29(0.96-1.73)$ \\
\hline Missing & $0.88(0.72-1.07)$ & $1.03(0.87-1.22)$ & $0.93(0.78-1.11)$ & $1.02(0.86-1.21)$ & $0.79(0.49-1.27)$ \\
\hline \multicolumn{6}{|l|}{ HER2 status } \\
\hline Positive & Reference & Reference & Reference & Reference & Reference \\
\hline Negative & $1.60(1.27-2.02)$ & $1.58(1.35-1.86)$ & $1.58(1.32-1.90)$ & $1.57(1.34-1.84)$ & $3.53(2.78-4.48)$ \\
\hline \multicolumn{6}{|c|}{ Axillary lymph node involvement } \\
\hline No & Reference & Reference & Reference & Reference & Reference \\
\hline Yes & $2.01(1.56-2.60)$ & $1.94(1.64-2.29)$ & $1.82(1.51-2.21)$ & $1.96(1.67-2.30)$ & $0.98(0.72-1.34)$ \\
\hline \multicolumn{6}{|c|}{ Lymph or vascular invasion } \\
\hline No & Reference & Reference & Reference & Reference & Reference \\
\hline Yes & $1.29(1.07-1.55)$ & $1.22(1.07-1.39)$ & $1.24(1.07-1.43)$ & $1.24(1.09-1.40)$ & $0.91(0.72-1.15)$ \\
\hline
\end{tabular}


Table 5: Estimated odds of imaging at specific body sites or all sites, for women with collaborative staging data (part 2 of 2)

\begin{tabular}{|c|c|c|c|c|c|}
\hline \multirow[b]{2}{*}{ Variable } & \multicolumn{5}{|c|}{ Body site; OR (95\% CI) } \\
\hline & All sites & Skeleton & Thorax & Abdomen or pelvis & Other \\
\hline \multicolumn{6}{|c|}{ Triple-negative disease } \\
\hline No & Reference & Reference & Reference & Reference & Reference \\
\hline Yes & $1.43(1.16-1.76)$ & $1.27(1.10-1.48)$ & $1.47(1.24-1.74)$ & $1.56(1.35-1.80)$ & $1.71(1.31-2.25)$ \\
\hline \multicolumn{6}{|c|}{ Preoperative breast US } \\
\hline No & Reference & Reference & Reference & Reference & Reference \\
\hline Yes & $1.65(1.34-2.02)$ & $1.44(1.20-1.72)$ & $1.63(1.36-1.96)$ & $1.62(1.35-1.93)$ & $1.67(1.00-2.79)$ \\
\hline \multicolumn{6}{|c|}{ Preoperative breast MRI } \\
\hline No & Reference & Reference & Reference & Reference & Reference \\
\hline Yes & $1.08(0.94-1.25)$ & $1.17(1.05-1.31)$ & $1.02(0.91-1.15)$ & $1.10(0.98-1.22)$ & $0.95(0.76-1.19)$ \\
\hline \multicolumn{6}{|l|}{ Surgery type } \\
\hline BCS & Reference & Reference & Reference & Reference & Reference \\
\hline Non-BCS & $1.39(1.22-1.58)$ & $1.29(1.17-1.42)$ & $1.27(1.14-1.42)$ & $1.42(1.29-1.56)$ & $1.13(0.93-1.39)$ \\
\hline \multicolumn{6}{|c|}{ System-related factors } \\
\hline \multicolumn{6}{|c|}{ Hospital type where surgery performed } \\
\hline Academic & Reference & Reference & Reference & Reference & Reference \\
\hline Community & $2.02(1.78-2.28)$ & $2.02(1.83-2.23)$ & $2.12(1.91-2.36)$ & $2.23(2.02-2.46)$ & $0.99(0.79-1.23)$ \\
\hline \multicolumn{6}{|l|}{ LHIN* } \\
\hline LHIN 3 & Reference & Reference & Reference & Reference & Reference \\
\hline LHIN 1 v. 3 & $5.13(3.73-7.06)$ & $2.50(1.96-3.19)$ & 7.49 (5.68-9.86) & $5.33(4.17-6.82)$ & $0.64(0.32-1.27)$ \\
\hline LHIN 2 v. 3 & $3.04(2.34-3.95)$ & $1.25(1.00-1.56)$ & $4.22(3.35-5.32)$ & $2.78(2.21-3.50)$ & $0.84(0.46-1.54)$ \\
\hline LHIN 4 v. 3 & $3.79(2.94-4.88)$ & $1.38(1.11-1.71)$ & $5.66(4.52-7.08)$ & $2.30(1.85-2.86)$ & $0.77(0.43-1.40)$ \\
\hline LHIN 5 v. 3 & $2.09(1.58-2.75)$ & $1.77(1.39-2.26)$ & $2.92(2.28-3.74)$ & $3.75(2.93-4.80)$ & $1.41(0.78-2.53)$ \\
\hline LHIN 6 v. 3 & $3.00(2.34-3.86)$ & $1.13(0.91-1.39)$ & $4.21(3.37-5.25)$ & $1.93(1.56-2.40)$ & $1.71(1.02-2.88)$ \\
\hline LHIN 7 v. 3 & $3.14(2.43-4.06)$ & $2.06(1.65-2.58)$ & $4.04(3.23-5.06)$ & $4.38(3.49-5.50)$ & $1.76(1.02-3.01)$ \\
\hline LHIN 8 v. 3 & $5.32(4.14-6.85)$ & $3.88(3.13-4.80)$ & $6.02(4.86-7.46)$ & $8.80(7.08-10.94)$ & $1.51(0.91-2.52)$ \\
\hline LHIN 9 v. 3 & $3.33(2.62-4.24)$ & $2.61(2.12-3.22)$ & $4.13(3.35-5.10)$ & $5.20(4.21-6.43)$ & $2.10(1.28-3.44)$ \\
\hline LHIN 10 v. 3 & $2.41(1.80-3.22)$ & $1.96(1.51-2.54)$ & $3.30(2.54-4.28)$ & $4.12(3.17-5.35)$ & $5.62(3.31-9.54)$ \\
\hline LHIN 11 v. 3 & $4.81(3.63-6.38)$ & $2.84(2.25-3.59)$ & $5.89(4.63-7.49)$ & $7.12(5.61-9.04)$ & $1.00(0.55-1.79)$ \\
\hline LHIN 12 v. 3 & $3.11(2.23-4.32)$ & $2.90(2.19-3.84)$ & $3.54(2.68-4.68)$ & $4.84(3.68-6.37)$ & $0.62(0.28-1.40)$ \\
\hline LHIN 13 v. 3 & $3.22(2.40-4.34)$ & $1.38(1.08-1.77)$ & $4.95(3.80-6.43)$ & $3.28(2.55-4.22)$ & $0.66(0.32-1.35)$ \\
\hline LHIN 14 v. 3 & $7.61(4.61-12.60)$ & $1.94(1.37-2.75)$ & $10.87(7.12-16.6)$ & $6.57(4.61-9.37)$ & $0.90(0.35-2.34)$ \\
\hline
\end{tabular}

with stage I disease should not undergo imaging, but such imaging was performed for $79.6 \%$ of the patients in our cohort. In stage II disease, where the ASCO document recommends no imaging, such imaging was performed in $92.7 \%$ of patients. An additional concern is that $23.8 \%$ of all imaging performed was confirmatory radiography of a body site that had already been imaged.

The current dataset was large enough to allow us to evaluate factors associated with increased imaging. Some of these factors may reflect char- acteristics associated with more aggressive tumours and therefore a higher pretest probability of detecting asymptomatic metastatic disease (e.g., younger patients, higher-stage disease, mastectomy). However, for other variables associated with increased use of imaging, such as more comorbidities, negative HER2 status, increased locoregional breast imaging and surgery in a community setting, there is no biological rationale for increased imaging.

Our findings, which are in keeping with those of other studies, raise the question of how to 
enhance adherence to evidence-based practice guidelines. Similar to another study, performed in the United States, ${ }^{23}$ we have shown that a range of patient, tumour and treatment characteristics are associated with increased imaging use, which may be useful in improving adherence. For example, certain adverse tumour characteristics such as stage, involvement of the axillary lymph nodes, lymphovascular invasion, negative HER2 status and tumour grade were all associated with increased utilization of imaging. This information is potentially useful because subgroups of patients with early-stage breast cancer who have these risk factors may have a higher rate of metastatic disease. However, at present, none of the commonly used guidelines include these characteristics, other than cancer stage, in their recommendations. ${ }^{4-8}$ The finding of significant variability in utilization across geographic regions and between community and academic centres may also represent gaps in guideline awareness, as well as opportunities for homogenization of practice across Ontario.

In general, physicians tend to be receptive to guidelines. Most believe that guidelines are a helpful source of advice, a valuable educational tool, a means for improving the quality of care and sufficiently practical to apply to their patients; however, guidelines do not reflect the potential legal and ethical implications of variable (nonadherent) practices. ${ }^{22,24,25}$ Additional work is needed to identify reasons why guidelines pertaining to perioperative imaging are not being followed. The factors evaluated should include factors related to patients, ${ }^{22}$ physicians ${ }^{26}$ and funding agencies. ${ }^{27}$

The strengths of the current study included use of a large cohort representing all women with primary operable breast cancer in Ontario. The dataset is likely to be representative, since all costs of imaging are covered by the provincial health care plan, and Ontario has a comprehensive collection of linked health administrative databases allowing linkage of patient data from diagnosis to postsurgical care. ${ }^{28-31}$ Furthermore, the Ontario Cancer Registry includes all breast cancer cases in Ontario.

\section{Limitations}

This study had several limitations. First, the data did not allow for determination of whether patients were symptomatic or whether symptoms developed within the 3-month period after surgery. However, the literature and clinical experience suggest that most patients undergoing surgery for newly diagnosed breast cancer are asymptomatic. ${ }^{10}$ Second, we could not determine the specific indication for imaging, and some tests may have been ordered for reasons other than breast cancer staging. Third, tumour characteristics for the full cohort were not available, and regression modelling was performed for the collaborative staging cohort only (about half of the total study cohort). To verify that there were no significant differences between cohorts, we performed multivariable analysis for both cohorts, using only those variables available for the full cohort, but the results were not significantly different. Fourth, because the data were contemporary, we were unable to compare longer-term outcomes such as survival between patients who underwent imaging and those who did not. Such a comparison represents an opportunity for future studies, along with an evaluation of the cost-effectiveness of imaging.

Another limitation of the current study is that while the 2001 Cancer Care Ontario guideline recommends isotopic bone scanning for patients with stage II disease, we have continued to consider this type of scanning as inappropriate, partly because more recent guidelines and the ASCO Choosing Wisely campaign do not recommend bone scans for patients with stage II disease. In addition, the methodology of the current study means that if the data for bone scans for patients with stage II cancer were removed from the analysis, then the number of initial skeletal radiography tests performed for patients with stage II disease would increase from 688 to 2021 and the number of initial skeletal MRI tests would increase from 357 to 905 .

\section{Conclusion}

Most women in Ontario with primary operable (early-stage) breast cancer undergo imaging to look for distant metastases, despite guidelines recommending against this practice.

The use of this imaging for women with stage I and II breast cancer, for whom evidence suggests that it is unnecessary, may be due in part to the lack of consensus among clinicians about the guidelines themselves. Further discussions about the appropriateness of guidelines in light of modern imaging techniques may be needed, especially as the data for the current study were collected from Jan. 1 2007, to Dec. 31, 2012. However, if guideline recommendations are to be implemented in practice, additional knowledge translation strategies are needed, as dissemination of clinical practice guidelines alone is not an effective method of changing physician practice behaviours. ${ }^{32}$ For example, identification of factors associated with imaging could allow targeted strategies to improve adherence. These strategies will also require patient engagement. The use of provincial datasets allows a unique 
opportunity to evaluate whether such strategies are effective at the broader population level.

\section{References}

1. Cancer facts and figures 2013. Atlanta: American Cancer Society; 2013. Available: www.cancer.org/acs/groups/content/@ epidemiologysurveilance/documents/document/acspc-036845.pdf (accessed 2015 May 8).

2. Brennan ME, Houssami N. Evaluation of the evidence on staging imaging for detection of asymptomatic distant metastases in newly diagnosed breast cancer. Breast 2012;21:112-23.

3. Crivello ML, Ruth K, Sigurdson ER, et al. Advanced imaging modalities in early stage breast cancer: preoperative use in the United States Medicare population. Ann Surg Oncol 2013;20: 102-10.

4. Myers RE, Johnston M, Pritchard K, et al.; Breast Cancer Disease Site Group of the Cancer Care Ontario Practice Guidelines Initiative. Baseline staging tests in primary breast cancer: a practice guideline. CMAJ 2001;164:1439-44

5. Clinical practice guideline BR-012 (version 2): staging investigations for asymptomatic and newly diagnosed breast cancer. Edmonton: Alberta Health Services; 2011 (revised 2012). Available: www.albertahealthservices.ca/hp/if-hp-cancer-guide-br012staging-investigations.pdf (accessed 2015 May 8).

6. Eastern Health Cancer Care clinical practice guidelines: staging of primary breast cancer. St. John's: Eastern Health; 2011. Available: www.easternhealth.ca/WebInWeb.aspx?d=4\&id $=1516 \& \mathrm{p}=1495$ (accessed 2015 May 8 ).

7. Clinical practice guidelines in oncology: breast cancer (version 1). Fort Washington (PA): National Comprehensive Cancer Network: 2014. Available: www.nccn.org/professionals/physician_gls/pdf/ breast.pdf (accessed 2015 May 8). Registration required to access content.

8. Senkus E, Kyriakides S, Penault-Llorca F, et al. Primary breast cancer: ESMO clinical practice guidelines for diagnosis, treatment and follow-up. Ann Oncol 2013;24 Suppl 6:vi7-23.

9. Barrett T, Bowden DJ, Greenberg DC, et al. Radiological staging in breast cancer: which asymptomatic patients to image and how. Br J Cancer 2009; 101:1522-8.

10. Simos D, Hutton B, Clemons M. Are physicians choosing wisely when imaging for distant metastases in women with operable breast cancer? J Oncol Pract 2014; Nov. 12 [Epub ahead of print].

11. Simos D, Hutton B, Graham ID, et al. Imaging for metastatic disease in patients with newly diagnosed breast cancer: Are doctor's perceptions in keeping with the guidelines? J Eval Clin Pract 2015;21:67-73.

12. Puglisi F, Follador A, Minisini AM, et al. Baseline staging test after a new diagnosis of breast cancer: further evidence of their limited indications. Ann Oncol 2005;16:263-6.

13. Choosing Wisely: an initiative of the ABIM Foundation. Philadelphia: ABIM Foundation; 2015. Available: www.choosingwisely .org/

14. Schnipper LE, Smith TJ, Raghavan D, et al. American Society of Clinical Oncology identifies five key opportunities to improve care and reduce costs: the top five list for oncology. J Clin Oncol 2012;30:1715-24.

15. Choosing Wisely Canada. Ottawa: Canadian Medical Association; 2014. Available: www.choosingwiselycanada.org/ (accessed 2015 May 8).

16. Edge S, Byrd DR, Compton CC, et al., editors. AJCC cancer staging manual. 7th ed. Chicago: American Joint Committee on Cancer; 2009.

17. Untch M, Konecny GE, Paepke S, et al. Current and future role of neoadjuvant therapy for breast cancer. Breast 2014;23:526-37.

18. Charlson ME, Pompei P, Ales KL, et al. A new method of classifying prognostic comorbidity in longitudinal studies: development and validation. J Chronic Dis 1987;40:373-83.

19. Postal code conversion file plus (PCCF+) (82F0086X). Ottawa: Statistics Canada; 2014. Available: www5.statcan.gc.ca/olc-cel/olc action?objId=82F0086X\&objType=2\&lang=en\&limit=0 (accessed 2014 Dec. 20).

20. Kralj B. Measuring rurality - RIO2008_BASIC: methodology and results. Toronto: Ontario Medical Association; 2009. Available: www.oma.org/Resources/Documents/2008RIO-FullTechnical Paper.pdf (accessed 2015 May 8).
21. Local Health System Integration Act, 2006: frequently asked questions about LHINs. Toronto: Ministry of Health and Long-Term Care; 2006. Available: web.archive.org/web/20120315221643/www .health.gov.on.ca/english/public/legislation/lhins/lhins_faq.html\#1 (accessed 2015 May 8).

22. Simos D, Hutton B, Graham ID, et al. Patient perceptions and expectations regarding imaging for metastatic disease in early stage breast cancer. SpringerPlus 2014;3:176.

23. Gold LS, Buist DS, Loggers ET, et al. Advanced diagnostic breast cancer imaging: variation and patterns of care in Washington state. J Oncol Pract 2013;9:e194-202.

24. Bleicher RJ. Breast magnetic resonance imaging as it is, in contrast to how we wish it to be. J Clin Oncol 2014;32:370-2.

25. Somerville MA. Ethics and clinical practice guidelines. CMAJ 1993;148:1133-7.

26. McWhirter E, Yogendran G, Wright F, et al.; Cancer Care Ontario Practice Guidelines Initiative. Baseline radiological staging in primary breast cancer: impact of educational interventions on adherence to published guidelines. J Eval Clin Pract 2007; 13:647-50.

27. Davis DA, Taylor-Vaisey A. Translating guidelines into practice. A systematic review of theoretic concepts, practical experience and research evidence in the adoption of clinical practice guidelines. CMAJ 1997; 157:408-16.

28. Health system information and data. Toronto: Cancer Care Ontario; 2013. Available: www.cancercare.on.ca/toolbox/system info/ (accessed 2015 May 8).

29. Health analyst's toolkit. Toronto: Ontario Ministry of Health and Long-Term Care; 2012. Available: www.health.gov.on.ca/english/ providers/pub/healthanalytics/health_toolkit/health_toolkit.pdf (accessed 2015 May 8).

30. Walters S, Maringe C, Butler J, et al. Comparability of stage data in cancer registries in six countries: lessons from the International Cancer Benchmarking Partnership. Int J Cancer 2013; 132:676-85.

31. Deyo RA, Cherkin DC, Ciol MA. Adapting a clinical comorbidity index for use with ICD-9-CM administrative databases. J Clin Epidemiol 1992;45:613-9.

32. Davis D, O'Brien MA, Freemantle N, et al. Impact of formal continuing medical education: Do conferences, workshops, rounds, and other traditional continuing education activities change physician behavior or health care outcomes? JAMA 1999;282:867-74.

Affiliations: Division of Medical Oncology, The Ottawa Hospital Cancer Centre (Simos, Dent, Clemons), Ottawa, Ont.; Department of Medicine (Simos, van Walraven, Fergusson, Dent, Clemons), University of Ottawa, Ottawa, Ont:; Ottawa Hospital Research Institute (Catley, van Walraven, Arnaout, McInnes, Fergusson, Clemons), Ottawa, Ont.; Institute for Clinical Evaluative Sciences (Catley, van Walraven), Toronto, Ont.; Department of Surgery (Arnaout) and Department of Radiology (McInnes), The Ottawa Hospital, Ottawa, Ont.; Department of Oncology (Booth), Queen's University, Kingston, Ont.

Contributors: All authors contributed to the conception and design of the study. Demetrios Simos and Christina Catley contributed to acquisition of the data, and all authors contributed to analysis and interpretation of the data. All authors reviewed and approved the final draft of the manuscript and agree to act as guarantors of the work.

Funding: This project was funded by a grant from the Patient Quality and Safety Committee, Department of Medicine and Division of Medical Oncology, University of Ottawa, Ottawa, Ont.

Disclaimer: This study was supported in part by the Institute for Clinical Evaluative Sciences (ICES), which is funded by an annual grant from the Ontario Ministry of Health and LongTerm Care (MOHLTC). The opinions, results and conclusions reported in this paper are those of the authors and are independent from the funding sources. No endorsement by ICES or the Ontario MOHLTC is intended or should be inferred. 